\title{
Geografía, historicidad y hermenéutica. Conversaciones sobre geografía con el geógrafo francés Dr. Alain Musset ${ }^{1}$
}

\author{
Andrés Núñez ${ }^{2}$
}

\begin{abstract}
AN. Estimado Alain Musset, en primer lugar deseo agradecer a nombre de la Revista de Geografía Norte Grande y del Instituto de Geografía de la Universidad Católica de Chile su interés por este diálogo. Desde mi punto de vista, una plática como esta bien puede considerarse un texto en sí mismo y, por tanto, es un buen complemento para el propósito de este número especial o dossier sobre la valorización y mejor comprensión de la Geografía histórica. Como es sabido, Ud. ha propiciado un trabajo interdisciplinario, interesándose por la historia desde la época de producción de su tesis doctoral. Con el tiempo, a esa plataforma ha agregado literatura, sociología e incluso, podríamos decir, la producción cinematográfica. Con ello, estimo, ha puesto énfasis en problemáticas históricas de las ciencias sociales, como lo es
\end{abstract}

\footnotetext{
1 Doctor en geografía por la Escuela de Altos Estudios en Ciencias Sociales de París, Francia. Profesor en la misma escuela, es director del Master Estudio comparativo del desarrollo y de la formación doctoral Territorios, Sociedades, Desarrollo. Como geógrafo especialista de la América Latina y de los estudios urbanos, ha trabajado en el campo de la relaciones ciudad/medio ambiente en una perspectiva histórica. Entre otros, ha publicado los siguientes libros: ¿Geohistoria o geoficción? Ciudades vulnerables y justicia espacial (Medellín: Universidad de Antioquia, 2009), Ciudad, Sociedad, Justicia: un enfoque espacial y cultural (Mar del Plata: EUDEM, 2010), Ciudades nómadas del Nuevo Mundo (México: Fondo de Cultura Económica, 2011), Le syndrome de Babylone. Géofictions de l'apocalypse (Paris: Armand Colin, 2012). Entrevista realizada en el mes de diciembre de 2012, en un diálogo abierto desde París y Santiago entre Alain Musset y Andrés Núñez. Bajo el marco del proyecto FONDECYT posdoctoral $N^{\circ} 3110027$.

2 Instituto de Geografía, Pontificia Universidad Católica de Chile (Chile). E-mail: E-mail: aanunezg@uc.cl
}

su posición frente a la ciencia. Pareciera que el asunto no tiene vuelta atrás y los vínculos entre las diversas disciplinas de las Ilamadas ciencias sociales resultan fundamentales e indispensables. Pero pareciera también que la llamada "ciencia", al menos en su significación tradicional, es decir, aquella que estima que existe un objeto separado del sujeto y por ende una certeza a develar, no otorga las respuestas esenciales que se buscó con su lenguaje en cada una de las Ilamadas, precisamente, ciencias sociales.

En este apartado, la idea es, entonces, explayarse sobre algunos asuntos que reformulen el problema y proyecten una geografía cuya historicidad (o sentido del espacio) parezca lo central, pero también, y por lo mismo, ella pueda proyectar una nueva racionalidad científica asociada a la hermenéutica del espacio, a sus discursos socioculturales y sus imaginarios geográficos. En definitiva, problemáticas en torno a nuevas propuestas epistemológicas de las ciencias sociales, algunas de las cuales ya se han visibilizado a partir de connotados escritores, varios de ellos geógrafos, como Soja, Harvey, Santos, Tuan, Massey, Wallerstein o el mismo Foucault. Este año que comienza los prolíferos Alicia Lindón y Daniel Hierneaux nos han brindado un nuevo título que, creo, precisamente apunta en esa línea y cuyo título es Geografía de lo imaginario. Estimo, en definitiva, que en la actualidad, la geografía requiere de un esfuerzo por identificar su propia producción de sentido, es decir, asimilarse también -y no únicamente- como un campo de trabajo en torno a los lenguajes o prácticas socio-culturales del espacio o, como Ud. mismo ha llamado, a la "construcción cultural 
de un objeto". Si está de acuerdo, entonces, iniciemos esta conversación por un asunto que aún hoy reúne a muchos geógrafos e historiadores. Me refiero al rol de cientificidad que ambas ramas adquieren en el siglo XIX y que, por cierto, perdura aún en determinados ámbitos. Es decir, que a través de la geografía y la historia es posible explicar y describir perspectivas del tiempo y el espacio en base a una realidad definitiva u objetiva. En otras palabras, un sujeto que descifra o naturaliza al objeto en sí mismo, como algo puro e incontaminado. ¿Cuánto de ese discurso disciplinario percibe $U d$. se encuentra aún instalado en el mundo académico o investigativo que gira en torno de la geografía y la historia?

AM. Pues, como su nombre lo indica, la geografía es desde el principio una ciencia de la descripción cuyo objetivo es transcribir, lo más exactamente posible, la materialidad y realidad del espacio terrestre. Esta práctica de geografía se inscribe indiscutiblemente en una perspectiva kantiana en la cual la geografía no es sino una "descripción razonada". En su Physische Geographie, publicada en 1802, el filósofo hacía una recapitulación de las nociones geográficas titulada "Conceptos matemáticos preliminares" en la cual, después de haber explicado el fenómeno de la rotación terrestre, se dedicaba a definir las herramientas básicas para situarse a la superficie de la tierra: polo, meridiano, ecuador, latitud, longitud, zona, círculos polares, trópicos, etc. En este sentido, Kant no se apartaba de las propuestas metodológicas expresadas casi 1.800 años antes por el geógrafo griego Estrabon para quien era preciso usar la geometría y la astronomía con el fin de describir los caracteres propios de tal o tal región, es decir su situación geográfica, su extensión, las distancias de un punto a otro, las temperaturas, el clima, etc. ${ }^{3}$.

Tal manera de entender el mundo, como Ud. Io ha subrayado, se basa en la idea según la cual el espacio es anterior al sujeto y donde dicho espacio tiene un valor a la vez universal y categórico. Para realizar su tarea de descripción del mundo "tal como es", los geógrafos clásicos desarrollaron herramientas

\footnotetext{
3 Disponible en Internet: http://www.mediterranees. net/geographie/strabon/l-1.html
}

y métodos con el propósito de cancelar la distancia entre el objeto representado y el destinatario de la información. El geógrafo -y el historiador siguió los mismos derroteros- desempeñaba entonces el papel de un intermediario objetivo que debía limitar a lo máximo su participación en los procesos de interpretación de la realidad, es decir, una distancia intelectual, que combinada con una proximidad física, era el crisol de una cientificidad asumida y pregonada.

Sin embargo, desde Las Historias de Herodoto hasta Google Earth, la supuesta objetividad del observador siempre ha sido un mito ya que el espacio geográfico no es sino un espacio social que se ubica en sistemas de representación a la vez técnicos, simbólicos y culturales. Aquello es clave. Es así como, en sus trabajos sobre las ciudades en la Francia moderna, Bernard Lepetit sacó a la luz la necesidad para el historiador de compartir el punto de vista de los contemporáneos para tratar de entender esquemas de representación que ya no son nuestros porque obedecen a categorías que evolucionaron en el tiempo (Lepetit, 1988). De manera provocativa, puso de manifiesto que era inútil buscar una adecuación perfecta entre el análisis histórico y su objeto, evocando a la vez el cuadro famoso de Magritte que declara «esto no es una pipa» (y con razón, puesto que solo se trata de la representación de una pipa), y la paradoja de Zénon, cuya flecha teórica nunca alcanzará su blanco porque debe pasar por todos los puntos de una línea derecha compuesta por un número infinito de puntos (Lepetit, 1988: 10).

De esta forma, Lepetit no dudaba en poner en tela de juicio esta visión cientifista de la historia basada en la ilusión que la realidad del pasado puede ser abarcada de manera holista y objetiva por un observador neutro que funda sus argumentos en la observación imparcial de las huellas del pasado. Lo mismo ocurre hoy día con la geografía humana y hasta los modelizadores más dedicados a los estudios cuantitativos saben que los resultados de sus trabajos no son sino la interpretación de una realidad virtual conformada por datos estadísticos subjetivos y ambiguos, cuando no son sencillamente erróneos. 
AN. Claro, como Ud. indica, en el caso de la historia aquello es particularmente evidente, porque su concepción de origen hegeliano ha permitido que ella sea comprendida comúnmente como un verdadero "cuaderno" donde queda definido "lo real". Paradójicamente, la historia de tipo hegeliana lo que olvida es su propia historicidad. Pero, la geografía no ha podido escapar a aquella suerte de paradigma cientificista de origen decimonónico.

AM. Pues, es cierto que los grandes geógrafos que representaban la escuela "clásica" nacida al final del siglo XIX reivindicaban, a través de la objetividad del observador, el carácter científico de su disciplina. En Francia, Paul Vidal del Blache condenaba así los relatos de los exploradores y conquistadores del siglo XVI que mezclaban lo anecdótico y lo maravilloso (las mirabilia, en latin) en sus descripciones de los Nuevos Mundos, diciendo que no rebasaban los límites trazados en su tiempo por Estrabon (Vidal de la Blache, 1948: 4).

A principios del siglo $X X$, uno sus más fieles alumnos, Albert Demangeon, solía criticar el discurso y los métodos de una geografía humana anticuada cuyos mejores representantes, hasta finales del siglo XVIII, se limitaban a acumular detalles destinados a suscitar la curiosidad del lector, sin tomar en cuenta la realidad de las sociedades descritas (Demangeon, 1947: 25). Por su parte, Jean Brunhes oponía de manera radical dos maneras de hacer geografía, dos maneras de ser geógrafo: "la vieja geografía se definía como la descripción de la tierra; la nueva geografía es realmente la ciencia de la tierra. No se limita a describir los fenómenos, sino que quiere explicarlos" (Brunhes, 1934: 36). Sin embargo, esta voluntad de empujar la geografía hacia una nueva era la estancó en una doble contradicción: se trataba a la vez de rechazar el paradigma de la descripción en favor de una explicación científica, reivindicando al mismo tiempo la necesidad de una presentación objetiva y racional de las regiones y sociedades estudiadas para entender sus relaciones y su organización interna.

Desde este punto de vista, el geógrafo no podía ser un elemento de su propia investigación (o de su propia historicidad en el marco de la historicidad de su disciplina) puesto que se encontraba "por naturaleza" exterior al contexto estudiado. Además, su estatuto de observador científico le prohibía tomar partido al interpretar la realidad (lo que hizo sin embargo Élisée Reclus al criticar en sus obras el sistema de explotación capitalista, el colonialismo y el imperialismo de las potencias europeas), puesto que la explicación de los hechos era una operación a priori neutra, fundada sobre principios, métodos y herramientas generales que pretendían ser universales. Al seguir los pensamientos de Kant y Hegel, esta trampa conceptual ha sido la base de la supuesta cientificidad de la historia y de la geografía que se desarrolló en Europa en el siglo XIX y al principio del siglo XX. Aunque aún perdura en ciertos ámbitos, existe un fuerte consenso de su posición idealista o hegeliana.

AN. Lo que Ud. formula, entonces, nos encamina a uno de los propósitos centrales de este diálogo, que es vincular la geografía con la hermenéutica, a partir de una geografía y una historia que en tanto proceso temporal no pueden escapar al lenguaje, en un sentido amplio, ya que ambas son parte también de una producción discursiva. Un discurso que es temporalidad como plantea Ricoeur ("Lo común de la experiencia humana es su carácter temporal"), pero una temporalidad finita, como lo ha dejado tan en evidencia Heidegger a partir del Dasein, esto es, el hombre reconocido en su propia finitud e historicidad. En otras palabras, la geografía y la historia se comprenden en una memoria cultural, en una historicidad desde donde se producen. Al respecto, el filósofo alemán H.G. Gadamer, aunque en una línea similar es factible incluir al propio Ricoeur, ha formulado una tesis muy relevante que ha marcado, creo yo, el devenir de las ciencias sociales en el siglo XX. Me refiero a la Hermenéutica ontológica, que, a grandes rasgos, plantea que solo nos movemos en un devenir de interpretaciones (aunque Nietzsche ya había adelantado algo al respecto) y que estas están delimitadas por una historia efectual que nos va definiendo. Con ello, él se asienta en una línea muy distinta a la precedente, al derribar toda pretensión o posibilidad de verdad para la ciencia. ¿Qué opina $U d$. al respecto, especialmente cuando aquella postura nos lleva a una espacialidad y temporalidad 
como el resultado de una construcción sociocultural?

AM. Ud. tiene razón y, desde mi punto de vista, formula asuntos muy enriquecedores para nuestra disciplina. La búsqueda de la realidad para el geógrafo es muy parecida a la búsqueda de la verdad para el filósofo. El problema es que a lo mejor no hay realidad sino realidades, tal como no hay una verdad sino muchas verdades que cambian según la cultura, el momento, la moda, el punto de vista del sujeto, etc., tal como lo recordaba Nietzsche al hablar de una "multitud móvil de metáforas, metonimias, antropomorfismos, en una palabra, una suma de relaciones humanas que fueron poéticamente y retóricamente aumentadas, transpuestas, adornadas, y que, después de un largo uso, le parecen a un pueblo firmes, canónicas y apremiantes" (Kremer Marietti, 1991: 123). A su juicio, las verdades no son sino meras ilusiones. Habla al respecto de "metáforas desgastadas" que perdieron su fuerza tal como ocurre con las monedas que perdieron su marca y que valen solo por su peso de metal.

AN. Muy interesante. Al existir multiplicidades de interpretaciones surgen, como bien apuntó Levi Strauss hace ya tantos años, un sinnúmero de realidades o culturas. Por favor, continúe.

AM. En efecto, el carácter subjetivo de las representaciones geográficas hace que pese a la fuerza de nuestras certidumbres científicas, cualquier sistema de ordenamiento espacial sea convencional y relativo tal como lo planteaba en su tiempo el sociólogo Émile Durkheim al recordarnos que el espacio, al contrario de los que pretendía Kant, no es sino el producto de una cultura: "Por sí mismo, el espacio no tiene ni derecha ni izquierda, ni arriba ni abajo, ni norte ni sur, etc. Todas estas distinciones vienen obviamente de que algunos valores emocionales distintos han sido afectados a las regiones. Y al igual que todos los hombres de una misma civilización se representan el espacio de la misma manera, es por supuesto necesario que estos valores emocionales y las distinciones que dependen de ellas les sean también comunes; lo que implica casi necesariamente que sean de origen social" (Durkheim, 1912: 21-22). Podemos al respecto tomar un ejemplo sencillo: la posición del norte arriba de los mapas topográficos no es sino la consecuencia de una elección ideológica puesto que el punto cardinal elegido para expresar "lo de arriba" no solo es una dirección sino también un símbolo expresando una jerarquía. Es tanto más simbólico cuanto que expresa una cosmovisión heredada de la antigüedad latina y griega, cosmovisión que no comparten otras civilizaciones. Para los chinos, por ejemplo, la aguja de la brújula no indica el Norte sino el Sur.

AN. Algo que, por ejemplo, J.B. Harley trabaja en forma tan brillante en su texto $L a$ nueva naturaleza de los mapas, una suerte de deconstrucción de las representaciones espacio-culturales reflejadas en los mapas.

AM. Cierto. Ahora bien, las representaciones sociales son un elemento central de la cultura, puesto que conforman el marco teórico que abarca los elementos de interpretación y los valores que dan un sentido a los "objetos" representados. Esta es la razón por qué la percepción y la representación del mundo material (la realidad) dependen de los procesos cognitivos y de las prácticas simbólicas que dominan en cada cultura, y dentro de una cultura, dentro de cada grupo social. Puesto que es imposible transmitir la realidad que nos rodea sin pasar por representaciones, la única objetividad posible reside en el reconocimiento explícito de los sistemas de valores que ordenan nuestra manera de ver y pensar el mundo. Es así como la geografía como disciplina universitaria es un excelente laboratorio para estudiar las relaciones entre las cosas y los signos o entre la realidad y sus representaciones. En efecto, la geografía, como corpus y catálogo de signos representantes, a la vez subjetivos y relativos, debe dar un sentido a las cosas representadas para que el espacio dicho "real" sea por fin considerado como el producto de un imaginario social, como lo decía el notable geógrafo André Bailly.

AN. Muy interesante. Lo planteado, desde mi punto de vista, colabora a comprender una geografía (y una historia) cuyo marco de orientación tenga que ver con aquel lenguaje discursivo a que se hacía mención. De este modo, la espacialidad es visibilizada desde una historicidad, desde una memoria que 
le da un sentido -subrayo un sentido- que monopoliza el lenguaje y que, por tanto, es aceptado socialmente. Aunque, por cierto, es factible identificar otros sentidos. Aquello, entonces, nos encamina hacia una nueva pregunta. Si está Ud. de acuerdo que ese sentido, esa imagen o ese valor dependerán del contexto sociocultural con que se moldee, y que, por lo mismo, ese sentido, es móvil e inestable, surge, entonces, una cuestión de fondo y que desde mi punto de vista es esta: ¿Cuál es, en definitiva, la cientificidad de la geografía?

AM. Es cierto que el espacio no es solo mi representación sino también bien la representación de mi cultura, del sistema cognitivo que suelo compartir con mi grupo de origen. Para resaltar el carácter performativo del lenguaje en este campo, podríamos recordar lo que decía Jean-Jacques Rousseau de las lenguas nacionales como expresión de un sistema de valores que desempeñan un papel central en las representaciones colectivas porque son el marco básico de la relación establecida entre los signos y las cosas. De hecho, a juicio del autor del Émile, las lenguas, al cambiar la forma de los signos, modifican también las ideas que representan. Por consecuencia, los pensamientos de cada individuo toman el color del idioma que comparte con su grupo o comunidad. De cierta forma, podríamos decir que la lengua no solo es la expresión de una ideología sino que es una ideología.

AN. Claro, porque el lenguaje al dejar de ser un instrumento o un mecanismo, asume una concepción, una visión, un sentido, una representación del mundo. El lenguaje viene a ser una preestructura del conocimiento. Como ha dicho Heidegger: "El lenguaje es la casa del ser". El notable biólogo chileno Humberto Maturana ha denominado a esta situación "lenguajear", para resaltar la producción narrativa de la experiencia humana, a partir de lo cual ha hecho un relevante aporte a las ciencias sociales.

AM. En efecto. Por aquella misma razón, el lenguaje de los geógrafos es el producto de su tiempo y de su cultura. En la tradición decimonónica, el carácter científico del enfoque geográfico parecía garantizado primero por la práctica del terreno, cuyo propósito era borrar la distancia entre el observador y el objeto observado, y por el uso de herramientas específicas (vocabulario especializado, mapas topográficos, fotografías consideradas por naturaleza "objetivas" al contrario de la pintura y el dibujo), destinadas a reducir la parte de lo subjetivo en la relación establecida entre el objeto representado y su destinatario. Es así como Raoul Blanchard, en su obra maestra Los Alpes Occidentales cuyo primer volumen ha sido publicado en 1938, llevó a cabo largas y meticulosas investigaciones que le empujaron a multiplicar los estudios de caso en espacios cada vez más pequeños, rechazando hasta el final de la obra observaciones más generales. Pues, nos ubicamos aquí en la perspectiva filosófica de Jean-Jacques Rousseau quien hacía hincapié en la necesidad del contacto inmediato con la realidad para comprender el mundo, eliminando por este medio los elementos y filtros intermedios entre el sujeto y el objeto. A su juicio, las cosas de por sí valen más que los signos, en particular para una geografía considerada básicamente como ciencia de la descripción: "En cualquier tipo de estudio, sin la idea de las cosas representadas, los signos representantes no son nada. Con todo, el niño siempre está limitado a estos signos, sin que nunca se pueda hacerle entender ninguna de las cosas que representan" (Rousseau, 1969: 73). Para ilustrar este desfase cognitivo entre el signo y la cosa, Rousseau tomaba el ejemplo del globo terrestre presentado a los alumnos como si fuera nuestro planeta, sin la leyenda de Magritte diciendo "esto no es la Tierra". De manera irónica y absurda, el novelista George Pérec puso en práctica esta voluntad de describir el mundo tal como es, limitando todas las interferencias posibles, en un ensayo publicado en 1975: Tentativa de agotamiento de un lugar parisino. Durante tres días, se quedó sentado en los cafés del barrio Saint-Sulpice en París. De estos puestos de observación, describe "lo que generalmente no se toma en cuenta, lo que no se observa, lo que no tiene importancia: lo que pasa cuando no pasa nada, sino el tiempo, la gente, los coches y las nubes". De manera tentativamente exhaustiva trató de Ilenar el catálogo de todas las cosas sensibles que conforman la realidad y/o la experiencia de un lugar sin lograr su meta imposible. 
¿Por qué recordar esta experiencia literaria para hablar de la cientificidad de la geografía? Básicamente porque nuestra disciplina, como las demás ciencias sociales, no necesita perder su tiempo en tratar de expresar y pregonar su legitimidad frente a las ciencias "duras" o "asociales". Sabemos que no estamos aquí solo para describir el mundo sino para explicarlo (y tal vez para transformarlo), tomando en cuenta las especificidades culturales de un espacio geográfico que ya no se puede pensar como universal. Por lo tanto, al reconocer la multiplicidad de la formas de territorialización de las sociedades humanas, según el momento histórico, el área cultural y los grupos, clases o comunidades que comparten (o se disputan) el mismo espacio, la geografía no pierde su valor científico, sino todo lo contrario.

AN. El asunto es tan apasionante como complejo, porque coloca, desde mi punto de vista, a la geografía en vínculo con la hermenéutica en tanto el espacio solo es posible de ser aprehendido, como Ud. lo ha destacado, desde la valorización que un grupo sociocultural le otorga y que no puede ser ni fijo ni único, por el contrario, es, como dijimos, más bien móvil e híbrido. Una suerte de espacio como texto (Aliste y Núñez, 2012) ¿Estamos frente a una geografía de las representaciones?

AM. En las ciencias sociales contemporáneas, el tema de las representaciones ha sido estudiado desde distintas perspectivas teóricas: en Francia, del lado de la psicología social, Moscovici, Jodelet y Abric hicieron hincapié en que las representaciones sociales son modalidades prácticas de conocimiento que dan sentido a la realidad y permiten establecer las formas de interacción, conocimiento y comunicación entre los sujetos. Como sociólogo, Bourdieu habló del poder performativo de las representaciones sociales para poner en tela de juicio la manera como no solo los grupos sino también los individuos pretenden imponer su forma de ver las cosas, es decir, una estrategia elaborada para conservar u ocupar una posición determinada en el espacio social.

AN. Aquello de Bourdieu me recuerda una frase de Foucault que me ha quedado grabada: "Hay una historia que permanece sin escribir, que es la de los espacios... que es al mismo tiempo la de los poderes/saberes...". En otras palabras, las estrategias a partir de las cuales se configuran los saberes espaciales.

AM. Por cierto. Pero los sistemas de representación no pueden entenderse sino en una perspectiva sobre todo cultural. La toma de conciencia de las apuestas culturales escondidas detrás de cualquier tipo de representación cartográfica o geográfica, debe permitirnos entender que no es posible abarcar la realidad del mundo ni agotar su significado. Como lo decía al respecto Émile Dardel en su obra maestra, L'homme et la terre, nature de la réalité géographique, al enfrentarse al carácter necesariamente subjetivo de las ciencias humanas, la geografía es por naturaleza una ciencia cuyo objeto sigue siendo inaccesible (como el blanco de la flecha de Zenon invocado por Bernard Lepetit), puesto que la realidad no puede encerrarse en una supuesta objetivad (Dardel, 1990). El problema es que, a mi juicio, el objetivo de la geografía no es alcanzar la realidad, sino entender cómo y por qué solemos construir cierta realidad, al alcance y a la medida de nuestras capacidades individuales y colectivas.

AN. Claro, este acento que Ud. coloca es, desde mi punto de vista, tan interesante como relevante para el panorama científico de una disciplina como la geográfica y que colabora, en cierta medida, a, podríamos Ilamarlo así, destraumatizar el problema.

AM. En geografía, ni las investigaciones de terreno (enfoque cualitativo) ni los análisis estadísticos (enfoque cuantitativo) pueden dar cuenta de una realidad "en sí" o a priori puesto que, como lo decía de manera provocativa Schopenhaueur para oponerse a Kant, el universo entero no es sino un objeto relacionado con un sujeto, o sea una percepción relacionada solo con una mente que percibe, es decir, una pura representación. Ahora bien, como geógrafo común y corriente, no me siento capacitado para oponerme a Schopenhauer, pero me parece que en este caso el filósofo alemán descarta demasiado rápidamente la dimensión colectiva de las representaciones. El sujeto que percibe nunca está solo frente a las cosas percibidas, sino 
que percibe el mundo a través de una cultura compartida, tal como lo recordaba Maurice Halbwachs en 1950, al cuestionar la noción de memoria colectiva (Halbwachs, 1967: 8). Es así como, al poner sistemáticamente en tela de juicio la relación entre el signo y la cosa, o sea entre la cosa representada y los sistemas de representación que le dan un sentido y un significado, la geografía nos enseña que la realidad no es un hecho sino un proceso.

AN. En efecto, no debemos olvidar la dimensión colectiva de las representaciones. En ello, me parece que Marx fue clave y precursor en su época cuando expuso que los individuos están insertos en una estructura social que los influye y los define como sujeto social. Lo formulado por $\mathrm{Ud}$. da cuenta de los cambios, de las movilidades de la geografía. En este contexto, surgen nuevas -y a veces no tan nuevas- perspectivas en torno a la disciplina, como, por ejemplo, el tema representacional del espacio. En Chile este punto de vista está menos explorado, pero existen geógrafos muy activos en esta línea, como por ejemplo Enrique Aliste. Me parece que en Europa Antoine Bailly también se ha movido en esta perspectiva. En América Latina destaco a Alicia Lindón y Daniel Hiernaux así como a Perla Zusman, Carla Lois, por nombrar algunos investigadores. Muchos de ellos no conciben una geografía separada de la sociología, la antropología, la filosofía, la historia. ¿ldentifica Ud. una suerte de corriente o paradigma que denote un giro en geografía que la permita situarse en esta plataforma interdisciplinaria que hemos venido reflexionando?

AM. Estoy completamente de acuerdo con lo que dice Ud. al respecto. Si bien todavía existe en América Latina una visión a veces demasiado tecnicista de la geografía, hace ya varias décadas que destacados geógrafos han pensado esta disciplina como una rama autónoma al interior de las ciencias sociales, en directa relación con la sociología, la antropología y por supuesto con la historia. Ud. ha citado a Enrique Aliste, investigador de la $U$. de Chile que ha trabajado sobre la evolución del pensamiento ambiental en la ciudad industrial de Concepción, con el propósito de poner en tela de juicio la noción de desarrollo sustentable. Con toda la razón Ud. mencionó también a Alicia Lindón, Daniel Hiernaux, Perla Zusman y Carla Lois, pero la lista de geógrafas y geógrafos que trabajan en este campo es mucho más larga. Pensemos por ejemplo en la gran escuela de geografía histórica de Brasil, con los aportes decisivos que hicieron Luis da Camara Cascudo, Mauricio Abreu, Wanderley Messias da Costa o Antonio Carlos Robert Moraes, entre tantos otros. Sin embargo, no creo que podamos hablar de un giro de la geografía contemporánea para entender los cambios de enfoque que la caracterizan. Al parecer, nos gusta hacer hincapié en las rupturas epistemológicas cuando en realidad, a mi juicio, tendríamos que hablar más bien de una combinación de continuidades, avances y ciclos que nos brindan siempre la oportunidad de volver a pensar de nuevo no solamente nuestra disciplina sino también los objetos y los conceptos que conforman sus campos de estudio.

AN. Muy interesante como enfoca el problema Ud. profesor Musset. El geógrafo belga radicado en México Daniel Hiernaux ha escrito recientemente en un interesante libro titulado Los giros de la Geografía Humana, que la geografía humana ya no puede ser considerada un anexo o una pieza suplementaria a una casa sólidamente construida -esto sería la geografía en su sentido decimonónico- sino que dada la condición social del espacio, ella es en sí misma un nuevo departamento. ¿Qué opina al respecto?

AM. Por supuesto concuerdo perfectamente con lo que dice Daniel Hiernaux, pero acá me parece necesario contextualizar, en tanto el problema me parece distinto en Francia puesto que en la arquitectura de nuestra Universidad, la geografía humana goza ya de un lugar específico en el marco más general de las ciencias sociales. Además, todas esas fronteras borrosas entre las diferentes ramas de la misma disciplina académica solo perjudican lo que debe ser, a mi juicio, la unidad fundamental de nuestra visión científica: el estudio de la inscripción territorial de los procesos sociales, entendida en la larga duración. Con todo, como geógrafo me siento como cualquier individuo que hace parte de cualquier comunidad: según el momento, el lugar, el enfoque y las circunstancias, me conformo con identidades múltiples, o sea geógrafo social, humano, cultural, histórico, 
urbano, latinoamericanista, geopolítico... No importa el adjetivo, lo que vale es el sustantivo. En otros términos, en este caso, ¡la esencia precede la existencia! Cabe mencionar que, por supuesto, estoy completamente de acuerdo con la idea de giros (y no de un giro en particular) para explicar la evolución o los cambios de una geografía humana que desde su nacimiento hasta su consolidación a fines del siglo XIX y sus procesos experimentados en el XX, no es única ni una sola.

AN. La pregunta anterior da pie, precisamente, para reflexionar sobre el rol de la geografía histórica. ¿Es la geografía histórica una disciplina marginal en los estudios de geografía? O, por el contrario, el desarrollo de la geografía humana en las últimas décadas, la ha posicionado cada vez con mayor fuerza hacia un espacio protagonista en las investigaciones de la disciplina? De hecho, algunos destacados geógrafos que participan en este dossier, como Perla Zusman por ejemplo, ha expresado la siguiente pregunta “Es necesario definir un campo especial para el estudio de la geografía histórica, o toda geografía es histórica?" Incluso en este mismo número espacial, Enric Mendizabal titula su trabajo del siguiente modo: “¿Hay geografía humana que no sea geografía histórica?".

AM. A decir verdad, es cierto que la palabra "geografía histórica" es a menudo menospreciada en Francia, cuando al contrario en los países anglosajones se trata de una ciencia social muy reconocida. ¿Cómo explicar esta situación de estancamiento? Pues, en Francia, la geografía histórica puede ser considerada como una disciplina académica que se ha apartado de los caminos contemporáneos de la geografía más avanzada. Roger Brunet, inventor de la controvertida geografía coremática, consideraba por ejemplo que si bien esta disciplina necesita usar métodos geográficos modernos para reconstruir las configuraciones geográficas desaparecidas, a su juicio generalmente no lo hace (Brunet, 1992).

Por supuesto no estoy de acuerdo con este punto de vista puesto que, por ejemplo, varios investigadores han podido desarrollar modelos espaciales para analizar la evolución en el tiempo de los territorios, tal como lo hizo Hervé Théry en el caso de Brasil, usando una gramática del espacio conformada de "cronocoremas" (Théry, 1986). Además, pienso que el propósito de la geografía histórica no es de excavar "configuraciones geográficas desaparecidas" (labor específica de la geografía retrospectiva), sino más bien de estudiar espacios que han evolucionado en el tiempo y que podemos identificar para entender los procesos históricos de transformación de los paisajes en relación con cambios sociales y culturales.

AN. Claro, no puedo estar más de acuerdo con Ud., en tanto la geografía histórica no es, por lejos, una reconstrucción de situaciones espaciales dadas en otros tiempos. Precisamente, la propia historicidad de la producción o fabricación de aquellos procesos territoriales complejiza el asunto.

AM. Ahora bien, las relaciones de esta rama peculiar de la geografía con la historia siempre han sido bastante ambiguas. Cabe recordar al respecto que las primeras clases que daba Fernand Braudel en la EHESS de París no eran de geografía histórica y tampoco de "geohistoria" sino de "historia geográfica". Por consiguiente, muchos historiadores consideran que los trabajos de los pocos geógrafos que miran hacia el pasado no son sino productos marginales de su disciplina académica. Por esta misma razón concuerdo con Perla Zusman y Enric Mendizábal para quienes la geografía es, por necesidad, histórica, pues me parece imposible entender los procesos sociales contemporáneos que se expresan en el territorio sin tomar en cuenta la larga duración que da un sentido, y de cierta forma una finalidad, a la actualidad. Es así como, por ejemplo, mis investigaciones actuales sobre la justicia social y espacial en el barrio indígena de Sutiaba (León, Nicaragua) se basan en mis estudios anteriores sobre el traslado de la ciudad española hacia dicha comunidad, Ilevado a cabo en 1610. Me ha Ilamado la atención, cuando participé al lado de la Junta directiva de la comunidad indígena y del Consejo de Ancianos a las ceremonias del 400 aniversario del traslado, hasta qué punto era necesario conocer toda la historia de este largo conflicto para entender las disparidades socioespaciales que conforman hoy en día los territorios urbanos y rurales del municipio de León. 
AN. Sí, la ciudad o lo urbano es justamente un escenario donde el panorama es especialmente evidente. Por ejemplo, complementando lo que Ud. indicaba, podremos percibir que un tipo o forma de ciudad, ilustrada podríamos llamarla, surgió en el siglo XVIII y no solo sirvió como patrón de dominio y control sino que además fue monopolizada por el discurso de superioridad valórica anclada en torno de lo racional, del orden, del centro de la narrativa de poder. Era el espacio donde recaía el Progreso y la Historia (así con mayúscula). Lo rural era, por tanto, atraso, marginalidad, salvajismo y, muy relevante, ahistoricidad. Yo diría que esa ciudad ya no existe, al menos no como discurso ilustrado y el espacio sufre una profunda transformación y cambio, en sus valores, en sus sentidos y proyecciones. Lo que deseo expresar, en definitiva, es que la espacialidad como la temporalidad no son asuntos lineales que "evolucionan" en un sentido teleológico.

AM. Sí, desde mi tesis doctoral sobre el desagüe del valle de México hasta mi programa actual de investigación sobre los territorios de la espera, en colaboración con el gran historiador de las ciudades brasileñas, Laurent Vidal, la ciudad siempre ha sido el tema central de mis estudios y preocupaciones. He podido cambiar de enfoque, escala, metodología o problemática, pero nunca he cambiado de objeto. Al trabajar sobre los traslados de ciudades en la América hispánica (Musset, 2010) me di cuenta hasta qué punto $U d$. tiene razón. La ciudad clásica no es solo una forma sino también (y sobre todo) un reflejo, una inmaterialidad. Cuando debaten sobre la posibilidad de abandonar el antiguo asentamiento para buscar un lugar más cómodo y tal vez más seguro para sus habitantes, los vecinos nos informan sobre lo que representa para ellos, en su vida cotidiana y sus imaginarios, la ciudad. Yo recuerdo un manuscrito que encontré hace años en la Biblioteca Nacional de Madrid y que trata de este problema, a raíz del terremoto que azotó la capital de la capitanía general de Guatemala en 1717. Para oponerse a la mudanza, los autores de la carta argumentaban que la razón de estado de una ciudad no consiste en el suelo y la tierra sino, de manera mucho más simbólica, en el bien público y la utilidad común de todo el reino (desde el punto de vista de las élites locales, por supuesto). En este sentido, no ponen el acento, el énfasis, en la materialidad del conjunto urbano (urbs en latín), sino en su expresión política o sea la civitas de los latinos, base cultural de lo que solemos Ilamar la civilización. El mejor ejemplo de esta relación especial que tenían los vecinos españoles con el cuerpo político representado por la ciudad es la manera que se usaba para matar de manera simbólica la ciudad abandonada: se le quitaba en primer lugar su campana, es decir su voz, su alma.

Ahora bien, es cierto que al cambiar de escala y de uso, para retomar las ideas de Henri Lefebvre sobre el valor de uso y el valor de intercambio, las ciudades modernas han perdido parte de su sentido. A menudo la civitas se esfumó y solo nos queda la urbs, es decir la forma urbana, o la apariencia de la ciudad. Es así como, al juntar en la misma zona condominios cerrados y centros comerciales, las agencias inmobiliarias pretenden asegurar la seguridad de los habitantes-consumidores de una ciudad cada vez más virtual o transformada en una simple "máquina de habitar" para volver a usar las palabras de Le Corbusier. En abril de 2008, me Ilamó la atención ver anuncios pregonados por compañías urbanizadoras en la ciudad de Santiago de Chile. Se trataba de valorar barrios privados ubicados en la periferia de la capital, porque eran "a pasos de todo", es decir al lado de un mall, con todas sus tiendas, sus servicios médicos y sus actividades de recreo. Ahora bien, en lugar de edificar condominios cerrados "a pasos de todo", me parece necesario volver a ordenar una ciudad "al paso de todos". De hecho, como ya lo he apuntado en mi libro de 2009 ¿Geohistoria o geoficción? Ciudades vulnerables y justicia espacial, me parece imprescindible rechazar un modelo urbano globalizado en el cual los espacios públicos son transformados en simples "áreas comunes" por empresas inmobiliarias que actúan como administradoras de ciudades sin ciudadanos. Al contrario, tenemos que pensar el espacio público como un "bien común" no solo de los vecinos sino también de los transeúntes y visitantes, si queremos en adelante devolverle a la ciudad su dimensión política, es decir su identidad colectiva.

AN. Muy interesante, porque las representaciones, los valores como bien dijo Ud. van mutando. Personalmente me resultan de 
sumo interés los planteamientos de Immanuel Wallerstein sobre la colonialidad del poder/ saber/ser, es decir, aquella perspectiva que plantea que gran parte de nuestro discurso está estructurado por determinados patrones de conocimiento y donde a estas alturas algunos de ellos resultan muy poco originales. En ese contexto, ¿cuál es la importancia de le otorga Ud. a las Ilamadas geografías poscoloniales en el ámbito de la geografía histórica/ cultural?

AM. En realidad, yo no hablaría de geografía poscolonial sino de estudios poscoloniales en general como cambio global de paradigma analítico para entender tanto el mundo contemporáneo como las configuraciones espaciales y sociales (en el sentido más amplio de la palabra) del pasado. Es cierto que los estudios de Wallerstein sobre el sistema mundo (Wold Systems Analysis) jugaron un papel decisivo en la apertura de nuevos caminos científicos que pudieron aprovechar tanto los historiadores como los geógrafos. Cabe recordar al respecto los trabajos realizados por grandes historiadores y antropólogos tales como Dipesh Chakrabarty (Provincializar Europa: el pensamiento poscolonial y la diferencia histórica), Homi K. Bhabha (Los lugares de la cultura: una teoría poscolonial), Arjun Appadurai (Después del colonialismo: Las consecuencias culturales de la globalización) o Sanjay Subrahmanian (Explorations in Connected History: From the Tagus to the Ganges), entre muchos otros. Sin embargo, los estudiosos quienes, desde por lo menos tres décadas, han trabajado el tema de las relaciones entre España (o Portugal) y sus dominios americanos desde una perspectiva comparatista, integrada y sistemática, ya habían planteado, tal vez sin expresarlo de manera tan clara como lo hizo Chakrabarty en 2000, la necesidad de pensar el mundo de manera diferente, con una pluralidad de centros y periferias. Al nutrirse de los aportes de los estudios coloniales, Serge Gruzinski profundizó así su itinerario intelectual con la publicación de su libro impactante Las cuatro partes del mundo. Historia de una mundialización (2004). Claro que no se trata abiertamente de un trabajo de geografía histórica. Sin embargo, al estudiar el desarrollo de las relaciones intercontinentales, el despegue de los intercambios económicos y culturales y la ampliación de los múltiples mestizajes que caracterizan esas sociedades atravesadas por viejos prejuicios y nuevas ideas, Gruzinski nos da a entender cómo han evolucionado y cambiado todo los territorios impactados por esta primera mundialización.

Yo recuerdo al respecto haber trabajado hace veinte años al lado de Joaquín Galarza, gran especialista de los códices prehispánicos. No se usaba en aquel entonces el término de estudios poscoloniales, sin embargo solíamos concordar en la necesidad de decentrar nuestra manera de ver y estudiar los procesos desencadenados por la llegada de los españoles en el Anáhuac de los Mexicas. Como yo estaba empezando el estudio de los mapas de la Relaciones geográficas del siglo XVI, íbamos buscando las huellas gráficas y simbólicas de los intercambios culturales entre conquistadores y conquistados en las pinturas de estas representaciones del territorio novohispano. Si bien se podía hablar de una aculturación de los indígenas por parte de los europeos, también quedaban evidencias claras de una aculturación inversa.

Ahora bien, en este contexto poscolonial tan complicado y conflictivo, tal vez podríamos proponer una alternativa a la aculturación, desviando de su sentido inicial otro término utilizado en su tiempo por la evangelización cristiana: la inculturación, o sea la adaptación del evangelio a las culturas locales para conquistar y salvar tantas almas "mal orientadas"4. De hecho, la palabra "aculturación" aplicada a la relación desigual entre dos culturas, se caracteriza por un prefijo (la preposición latina ad) por la cual se determina un movimiento en sentido único que pone de manifiesto la dominación de un grupo sobre otro grupo. Al usar la inculturación de manera poscolonial, se trataría de devolver a la metáfora del mestizaje cultural su carácter fusional usando un prefijo tanto aumentativo como incorporativo (in). En este sentido, la inculturación no sería el resultado de una invasión o una intrusión sinónima de pérdida y privación, sino un proceso de reparto y apropiación de nuevas identidades que se suman a las anteriores. Al fin y al cabo, este es el proceso que podemos observar en territorios donde se asentaron en la larga duración so-

\footnotetext{
4 Ha sido el tema de la querella de los ritos que opuso Roma a los jesuitas de China, en el siglo XVII.
} 
ciedades con características culturales distintas y a veces antagónicas.

AN. Para terminar, una última pregunta profesor Musset, aunque tal vez sea un balance de buena parte de lo formulado con antelación. Al buscar trabajar con objetos de análisis menos objetivos, menos cuantitativos, menos "reales" si se quiere, estamos en una línea de análisis donde la discursividad, el lenguaje sociocultural forman parte de una historicidad cuya base no es más que una imaginación temporal o como ha dicho García Canclini, "una reconstrucción incesante del objeto". Aquello hace que recuerde a Magritte, ya citado por Ud., con aquello de "Esto no es una pipa" o a Alfredo Jaar con su notable intervención en plena Nueva York de "Esto no es América". Allí donde vemos una certeza o una materialidad, en definitiva no sería más que un sentido o valor de lo que ha sido una producción o fabricación sociocultural, una representación que solo es verdadera en tanto acuerdo social. Así, una cordillera puede ser una frontera y una frontera puede ser un límite (ambas producciones del siglo XIX en Chile), una historia puede ser nacionalidad (las historias de escala nacional), en fin, un espacio ocupado puede ser "desierto" (Araucanía chilena y especialmente la Patagonia argentina). Los ejemplos son innumerables $y$, por lo mismo, objeto de estudio e investigación existen muchos en una geografía de lógica hermenéutica. Ud. mismo ha planteado el problema en relación a las representaciones de las ciudades en base a sus contextos culturales. Por tanto, pareciera que los imaginarios son esenciales, la identificación de la producción del significado del espacio parece clave, especialmente, si consideramos que aquello, en definitiva, constituye memoria. Aquí, y con esto termino mi planteamiento, surge desde mi punto de vista un asunto central y que fue buena parte de la preocupación de Foucault: ¿A quién le pertenece aquella memoria construida? ¿Quién o cómo se naturaliza o esencializa el espacio, quedando la sensación que hubiese sido desde siempre igual? En ello, estimo, se olvida la textualidad histórica del espacio, su narrativa móvil y finita, en fin, su producción de sentido. Por cierto, esta pregunta me resulta muy importante en una geografía que, como hemos venido reflexionando, no es ajena de una búsqueda de su propia significación.
AM. Si bien la cuestión planteada por $U d$. es de actualidad, se inscribe sin embargo en un plazo más largo. Ya en 1950, Maurice Halbwachs había planteado el problema de una teorización de la memoria colectiva. A su modo de ver, toda sociedad se divide en una multiplicidad de grupos que elaboran su propio análisis de los acontecimientos históricos y su propia conservación de los recuerdos. Las referencias individuales no pueden entenderse sino en el contexto de una estructura más amplia cuyos elementos comparten a la vez los valores morales y políticos así como el sistema de pensamiento. Por consecuencia, a juicio de Halbwachs, cada aspecto, cada detalle de un lugar particular tiene un sentido que solo es inteligible para los miembros del grupo que lo habita o que lo ha habitado.

Ahora bien, como lo observa Giovanni Levi, hoy en día incluso la memoria ha cambiado de sentido y quizá de naturaleza. La aceleración de los procesos de individualización que caracterizan nuestras sociedades modernas produce una memoria dispersada, fragmentada, cuyos diferentes elementos ya no están vinculados a una tradición compartida o a una experiencia común: "Es la memoria de cada uno, no la de un grupo o de un pueblo, que entra continuamente en escena: ya no una historia comunicable pero una autobiografía, ya no el pasado de la sociedad pero una multitud de fragmentos y objetos separado" (Levi, 2001: 31). Consecuencia directa de esta abundancia de memorias y relatos se multiplican los lugares encargados de conservar la huella de grupos cuya definición es cada vez más estricta y cuyas dimensiones son cada vez más reducidas. Tenemos entonces que tomar en cuenta las nuevas perspectivas que se desprenden de esta nueva relación entre el territorio y la memoria, más allá de los famosos "lugares de memoria" diseñados en su tiempo por Pierre Nora. Voy a publicar al respecto, en la revista española de sociología Empiria, un artículo titulado "Memorias íntimas y espacio social", en el cual intento analizar cómo se construye una memoria de los lugares comunes y corrientes de la ciudad relacionados con las prácticas diarias de una familia. Ahora bien, esos pequeños lugares destacados se ubican en un tiempo social más amplio y expresan la apropiación virtual 
y limitada en el tiempo de un espacio público por una memoria privada.

AN. Su argumento me recuerda al geógrafo chino Yi Fu Tuan.

AM. Precisamente, para allá iba. Esta aproximación sensible de los lugares y hechos sociales puede inscribirse en la perspectiva de la geografía teorizada por Yi-Fu Tuan quien estudió cómo los individuos, en un grupo y una cultura, perciben y construyen su realidad topológica gracias a un flujo continuo de alimentación simbólica entre memoria y anticipación o proyección (Tuan, 2006). Al trabajar también sobre las distintas maneras de habitar el espacio (y de ser habitado por el mismo), el geógrafo francés Olivier Lazzarotti ha identificado al individuo no solo como actor sino también como autor de su propia geografía, es decir, de su inscripción en el territorio. Este concepto de "autor", inspirado de Michel Foucault, nos permite comprender mejor cómo el habitante de un lugar (incluso si solo lo habita de manera efímera), puede inscribirse en dicho lugar de manera a la vez singular y sintética a partir de las herramientas que comparte con los miembros del grupo al cual pertenece.

Con todo, tal vez sería necesario volver a lo que decía Halbwachs sobre la memoria colectiva cuando apuntaba que, al insertarse en una porción de espacio, cualquier grupo o sociedad la transforma a su imagen para luego conformarse con la imagen del territorio que ha producido. De cierta forma, y para cerrar así de manera muy provisional el debate sobre las interacciones entre los grupos sociales, su memoria colectiva y sus territorios, podríamos decir que si bien los lugares son lo que hacemos de ellos, ellos hacen de nosotros lo que somos.

\section{Referencias bibliográficas}

LEPETIT, B. Les villes dans la France moderne (1740-1840). París: Albin Michel, 1988.

LEPETIT, B. Les représentations de la viIle. Pour quoi faire? In: WALTER, F. (editor). Vivre et imaginer la ville, XVIIle-XIXe siècle. Genève: Zoé, 1988, p. 10.
VIDAL DE LA BLACHE, P. Principes de géographie humaine. Paris: Armand Colin, 1948, p. 4.

DEMANGEON, A. Problèmes de géographie humaine. Paris: Armand Colin, 1947, p. 25.

BRUNHES, J. La géographie humaine. Félix Alcan, 1934, p. 36.

KREMER MARIETTI, A. Le livre du philosophe (Kritische Studienausgabe, VII, 880-881). Paris: Flammarion, 1991, p. 123. Disponible en Internet: http://dogma.free.fr/txt/AKMNietzsche-meta.htm

DURKHEIM, E. Les formes élémentaires de la vie religieuse, 1912, p. 21-22. Disponible en Internet: http://classiques.uqac.ca/ classiques/Durkheim_emile/formes_vie_religieuse/formes_vie_religieuse.html

ROUSSEAU, J.J. Émile ou l'éducation. Paris: La Pleïade, 1969 [1762], p. 73.

ALISTE, A. y NÚÑEZ, A. Las fronteras del discurso geográfico: el tiempo y el espacio en la investigación social. Documento presentado en el Seminario del Doctorado en Ciencias Sociales de la Facultad de Ciencias Sociales de la Universidad de Chile, diciembre 2012 (Inédito).

DARDEL, E. L'homme et la terre, nature de la réalité géographique. Paris: CTHS, 1990 [1952].

HALBWACHS, M. La mémoire collective. Paris : PUF, 1967 [1950], p. 8.

BRUNET, R. Les mots de la géographie. Reclus-La Documentation française. MontpeIlier-Paris, 1992.

THÉRY, H. Brésil, un atlas chorématique. Montpellier: Fayard/Reclus, 1986.

MUSSET, A. Ciudades nómadas del Nuevo Mundo. México: FCE, 2010.

LEVI, G. Le passé lointain, sur I'usage politique de I'histoire. En: HARTOG, F. \& REVEL, J. Les usages politiques du passé. Paris: Éditions de l'EHESS, 2001, p. 31.

TUAN, Y.-F. Espace et lieu, la perspective de l'expérience. Paris: Infolio, 2006. 